\title{
LOS INICIOS DEL SEMINARIO DE NUESTRA SEÑORA DE LA ASUNCIÓN DE GUATEMALA, 1598-1620. UN PROYECTO EXITOSO Y POCO TRIDENTINO
}

\author{
POR \\ Leticia Pérez Puente \\ Instituto de Investigaciones sobre la Universidad y la Educación \\ de la Universidad Nacional Autónoma de México.
}

\section{RESUMEN}

Este trabajo atiende al estudio de la fundación y primeros años de vida del seminario conciliar de la diócesis de Guatemala, creado en 1598 por el obispo fray Gómez Fernández de Córdoba. El objetivo es mostrar cómo la labor continuada y los escasos conflictos que enfrentó en ese entonces, se debieron a que, a diferencia de las fundaciones que le precedieron, el seminario de Nuestra Señora de la Asunción no inició como un proyecto propiamente episcopal, debido a la estrecha vinculación que mantuvo con los poderes reales, así como a las particulares constituciones dictadas en su fundación. Es este un ejemplo más de la lenta introducción y adaptación sufrida por la legislación tridentina en América.

PalABRAS ClAVE: Seminarios conciliares, formación del clero, reforma eclesiástica en Indias.

\section{THE BEGINNINGS OF THE SEMINARY OF OUR LADY OF THE ASSUMPTION OF GUATEMALA, 1598-1620. A SUCCESSFUL AND HARDLY TRIDENTINE PROJECT}

\begin{abstract}
This work considers the study of the foundation and first years of existence of the council seminary of the Guatemala diocese, created in 1598 by Bishop Fray Gómez Fernández de Córdoba. The aim is to point out how the constant work thescarce conflicts which it faced in those days owing to the fact that, and unlike
\end{abstract}


the preceding foundations, the seminary of Our Lady of the Assumption was not begun exactly as an Episcopal project, due to the close connection it maintained with the royal powers, as well as the particular constitutions enshrined in its foundation. This is another clear example of the slow introduction and adaptation undergone by the tridentine legislation in America.

KEY WORDS: Council seminaries, clergy formation, ecclesiastical reform in the Indies.

Recibido/Received 2010-12-02

Aceptado/Accepted 2011-01-05

Cuando en 1597 el anciano obispo de Guatemala, fray Gómez Fernández de Córdoba, ordenó la fundación del colegio de Nuestra Señora de la Asunción, los seminarios conciliares tenían en América una historia de esfuerzos por asentarse. ${ }^{1}$ En Quito el colegio que 30 años atrás iniciara con tantos trabajos fray Pedro de la Peña, se había consumido para dar paso a una institución distinta, controlada por la Compañía de Jesús. ${ }^{2}$ Lo mismo había sucedido en Santa Fe, donde, debido a las penurias económicas, el obispo Zapata de Cárdenas clausuró en 1586 su colegio de San Luis de Tolosa, aunque luego sería reinstaurado por Bartolomé Lobo Guerrero en 1605, pero ahora bajo la dirección de los jesuitas. ${ }^{3}$ Por su parte, el limeño de Santo Toribio de Astorga había abierto sus puertas en 1590 y, siete años después, sólo sobrevivía a instancias de Mogrovejo, quien peleaba denodado con su cabildo y las órdenes religiosas para mantenerle abierto. ${ }^{4}$

En marcado contraste con aquellos colegios, el seminario de Nuestra Señora de la Asunción tuvo una rápida y relativa facilidad en su fundación. A diferencia de los que le precedieron pronto contó con rentas estables, alojó colegiales en edificio propio e impartió cátedras, además nunca se vio precisado a cerrar,

\footnotetext{
${ }^{1}$ Este trabajo ha sido posible gracias al apoyo del señor Alejandro Conde, archivero del AHAG, a quien agradezco sus atenciones y las facilidades que me brindó para la consulta de los documentos de ese acervo. El término colegio o seminario hace referencia a la comunidad o corporación de niños y jóvenes que viven de forma conjunta. Eran hospederías donde no necesariamente había cursos y podían estar bajo la dirección de un obispo, alguna orden religiosa o un seglar. Por su parte, los seminarios conciliares o tridentinos, llamados así por haber sido ordenados crear por el concilio de Trento, eran instituciones que se distinguían de las anteriores porque debían mantenerse de rentas eclesiásticas y estar bajo el gobierno de quien fuera obispo de la diócesis; teóricamente debían tener cátedras, aunque no todos las poseyeron, pues en algunos casos sus colegiales asistían a las universidades o colegios de la ciudad.

${ }^{2}$ Pérez Puente, L. 2010. «Un seminario conciliar entre dos iglesias. Quito 1565-1583», en J. Correa (ed.), Facultades y Grados. X Congreso internacional de Historia de las universidades hispánicas. II: 219-242. Valencia: Universidad de Valencia.

${ }^{3}$ Hernández de Alba, G. 1969. Documentos para la historia de la educación en Colombia, 15401653. I: 67-70. Bogotá: Patronato colombiano de Ciencias y Artes.

${ }^{4}$ Vargas Ugarte, R. 1969. Historia del seminario de Santo Toribio de Lima, (1591-1900). Lima: Empresa gráfica San Martí; Pérez Puente, L. 2012. «La fundación del seminario conciliar y el fortalecimiento de la jurisdicción episcopal, Lima 1564-1603», en R. Aguirre Salvador (ed.), Espacios de saber, espacios de poder. Iglesia, universidades y colegios en Hispanoamérica, siglos XVI-XIX: 74-97. México: Instituto de Investigaciones sobre la Universidad y la educación, UNAM.
}

Hispania Sacra, LXIV

129, enero-junio 2012, 187-210, ISSN: 0018-215-X, doi: 10.3989/hs.2012.006 
ni debió ceder su administración a la Compañía de Jesús, al menos durante el periodo virreinal.

Esa estabilidad y rápido desarrollo, que bien podrían calificarle de exitoso, se debieron a que el seminario de Guatemala contó con las experiencias vividas en otras diócesis, así como con los privilegios concedidos a ellas. En efecto, para 1598, a más de las directivas canónicas, se habían dictado diversas cédulas reales, limitando la jurisdicción de Audiencias y virreyes y confirmando la propia de los obispos en el gobierno y dirección de los colegios. Así como otras que conminaban a los renuentes cabildos catedralicios y a las órdenes religiosas a pagar lo que les correspondía para su sostenimiento. ${ }^{5}$ Por otra parte, contribuyó también al éxito del seminario guatemalteco el que, a diferencia de otros, éste nació en estrecha vinculación con los poderes reales, y al hecho de que sus primitivas constituciones le dotaron de una gran autonomía respecto de la figura episcopal, dejando así constancia de la rápida transformación sufrida por estos establecimientos en América.

En fin, el éxito en la fundación y primeros años de funcionamiento del Seminario de Nuestra Señora de la Asunción, último de los indianos creados en el siglo XVI, se debió a que no fue un proyecto propiamente episcopal y, por tanto, tampoco cabalmente tridentino. ${ }^{6}$

\section{UN PRELADO DISTANTE}

Los trabajos sobre los seminarios conciliares casi siempre suelen iniciar mencionando los acuerdos tomados en la sesión XXIII del concilio de Trento. En ella se establecieron los objetivos de estos establecimientos: «mantener, educar e instruir a quienes serían los encargados del ministerio eclesiástico». Se dispusieron las características de sus alumnos: jóvenes de no menos de doce años, de legítimo matrimonio, con inclinación al sacerdocio, y la instrucción que recibirían: gramática, canto, sagrada escritura, cómputo eclesiástico, «las fórmulas de administrar los Sacramentos, en especial lo que conduce a oír las

\footnotetext{
${ }^{5}$ Sobre las contribuciones véase cédula de septiembre 22 de 1590, AGI, Quito, 209, L. 1, f. 84v-85. Sobre la fundación de seminarios y su gobierno cédulas de junio 8 y 22 de 1592, AGI, Indiferente, 427, L. 30, f. 435v-436v y AHN, Códices, L. 731. En este último también la cédula para que los seminaristas sean preferidos en las parroquias de septiembre 21 de 1592 . Cédula sobre el gobierno de los seminarios de diciembre 22 de 1593 en AGI, Quito, 211, L. 3, f. 69-69v. Así como las contenidas en el título 23, leyes 1 a 5 y 7 en 1841. Recopilación de leyes de los reinos de las Indias mandadas imprimir y publicar por la Magestad Católica del rey Don Carlos II. Madrid: Boix.

${ }^{6}$ De opinión contraria fue Vergara Ciordia quien al hablar de este seminario señaló que pudo desempeñar su finalidad sin apenas altibajos y con bastantes frutos debido a que desde sus comienzos gozó de «estabilidad económica y episcopal», lo cual atribuye a la estabilidad de las rentas decimales y a las breves sedes vacantes. Vergara Ciordia, J. 2004. Historia y pedagogía del seminario conciliar en Hispanoamérica, 1563-1800: 196-197. Madrid: Dykinson.
} 
confesiones» y todo aquello mandado por el obispo. Se especificaron también los lugares donde podrían ser erigidos, sus formas de gobierno y los recursos eclesiásticos para su financiamiento. ${ }^{7}$

De igual manera, al hablar de estos colegios suele aludirse a los trabajos y a la personalidad de los obispos fundadores, para mostrar el cumplimiento de los mandatos tridentinos y la fortaleza de sus respectivos gobiernos, pues estas instituciones tendían a beneficiar a la figura del obispo y la conducción espiritual y moral de su diócesis. Los clérigos allí formados estarían a su servicio, serían sus futuros provisores, sus vicarios, sus letrados y sus capitulares, en fin, los encargados de dar continuidad a los proyectos episcopales. De igual modo, la fundación de seminarios en América suele remitir a la capacidad de los obispos de proveer a los criollos de beneficios eclesiásticos y su avance en el control o secularización de las doctrinas indígenas que estaban a cargo del clero regular.

No obstante esa tradición historiográfica, los estudios sobre el seminario de Nuestra Señora de la Asunción suelen iniciar mencionando la cédula real de 1592 que ordenó la creación de los seminario tridentinos en Indias, ${ }^{8}$ y sin ahondar en la figura de fray Gómez Fernández de Córdoba, se limitan a señalar que éste ordenó su creación y lo dotó de estatutos que, por lo demás, en breve serían reformados. ${ }^{9}$

Ello se debe a que la fundación del seminario conciliar no parece haber sido una pieza clave en la política episcopal desplegada por aquél tercer obispo de Guatemala. De hecho, Ramón A. Salazar, autor de la Historia del desenvolvimiento intelectual de Guatemala, dudó abiertamente de su participación en la fundación del seminario. «...está bien probado -escribió- que, por encontrarse enfermo dicho señor obispo en esa época, no pudo más que iniciar las constituciones del seminario; y como quiera que al poco tiempo muriese dicho señor, la erección no tuvo efecto, ciertamente, sino hasta el año de $1601 » .{ }^{10}$

Las afirmaciones de Ramón A. Salazar parecen estar influidas por la obra de Antonio de Fuentes y Guzmán, quien presentó a Fernández de Córdoba como

${ }^{7}$ 1785. El Sacrosanto y Ecumenico Concilio de Trento, traducido al idioma castellano por Don Ignacio López de Ayala, agrégase el texto latino corregido según la edición auténtica de Roma, publicada en 1564: Ses. XXII, cap. 18. Madrid: Imprenta Real.

${ }^{8}$ AGI, Indiferente, 427, L. 30, f. 435v-436v.

${ }^{9}$ Salazar, R. A. 1897. Historia del desenvolvimiento intelectual de Guatemala. La colonia. I. Guatemala: Tipografía nacional; González Orellana, C. 1960. Historia de la Educación en Guatemala. México: Costa Amic; Mata Gavidia, J. 1954. Fundacion de la universidad en guatemala, 1548-1688. Guatemala: Editorial universitaria; Suñe Blanco, B. 1997. «La educación en Guatemala (s. XVI) como un proceso de enculturación-aculturación», en A. Jiménez (ed.), Antropología histórica: la Audiencia de Guatemala en el siglo XVI: 369-394. Sevilla: Universidad de Sevilla; Vergara Ciordia, J. 2004; Vergara Ciordia, J. 2005. «Datos y fuentes para el estudio de los seminarios conciliares en Hispanoamérica: 1563-1800». Anuario de Historia de la Iglesia 14: 239-300.

${ }^{10}$ Salazar, R. A. 1897: 36. Ese año ocupó la mitra guatemalteca fray Juan Ramírez de Arellano, pero ningún autor alude a su intervención en la marcha y consolidación del seminario tridentino.

Hispania Sacra, LXIV

129, enero-junio 2012, 187-210, ISSN: 0018-215-X, doi: 10.3989/hs.2012.006 
un obispo más interesado en promover a las órdenes religiosas que en fomentar el desarrollo de la clerecía secular. En la Recordación florida..., terminada hacia 1689, señaló que los frailes recibieron del obispo un «excesivo e inmoderado favor que muy en breve los hizo dueños de los curatos que se quitaban al clero». ${ }^{11}$

Fray Gómez Fernández de Córdoba pertenecía a la orden de San Jerónimo, y quizá se encontraba en el monasterio de Córdoba -a donde se retiró su abuelo «el Gran capitán» en los últimos años de su vida-cuando fue nombrado obispo de Nicaragua en 1568. Tres años después, el Consejo se quejaría de cómo, habiéndose hecho grandes instancias para que fuese a residir a su sede, había detenido su partida, e incluso había pretendido renunciar al obispado, diciendo que por ser tierra caliente era contrario a su salud. ${ }^{12}$

Los argumentos no fueron aceptados, y para 1572 se le ordenó embarcarse en la primera flota o de lo contrario se procedería contra él con pena de «temporalidades y de ser habido por ajeno y extraño de estos reinos». ${ }^{13} \mathrm{~A}$ pesar de la insistencia del Consejo para que ocupase su sede, se le mantuvo muy poco tiempo en Nicaragua, pues para junio de 1574 fue presentado como obispo de Guatemala. $^{14}$

Una de las primeras tareas del nuevo obispo fue restablecer la autoridad episcopal, afectada por los conflictos políticos que caracterizaron el gobierno de su antecesor, Bernardino de Villalpando (1564-1570). Este prelado había pretendido tomar a su cargo la compleja labor de adaptar la legislación tridentina a su diócesis por medio de un sínodo diocesano, ${ }^{15}$ lo cual lo enfrentaría con la Audiencia y el clero regular del obispado. Sus disputas se debieron a que con la intención de llevar a la práctica lo estatuido en el sínodo, despojó a los franciscanos de las parroquias que administraban en una de las provincias y lo intentó en otras dos, despachando edictos con graves penas. ${ }^{16}$

En sus quejas, el clero regular acusaba al obispo Villalpando de malos tratos y de desatender la disciplina de los clérigos seculares, haciendo caso omiso de los delitos y excesos cometidos por éstos contra los indios. Se decía que

${ }^{11}$ Fuentes y Guzmán, A. F. 1933. Recordacion florida discurso historial y demostración natural, material, militar y política del Reyno de Guatemala. III: 321. Guatemala: Tipografía nacional.

${ }^{12}$ Quejas contra el obispo por no ir a residir en su sede, mayo de 1571, AGI, Indiferente, 738, N. 24, f. 124

${ }^{13}$ Real cédula a fray Gómez de Córdoba, obispo de Nicaragua, encargándole que se embarque en la primera flota que salga para Tierra Firme y Nueva España, abril 24 de 1572, AGI, Indiferente, 426, L. 25 , f. $177 \mathrm{v}$.

${ }^{14} \mathrm{Al}$ obispo de Nicaragua que esta presentado al obispado de Guatemala, sobre que vaya a residir, junio 3 de 1574, Guatemala, 386, L. 2. F. 24-24v.

${ }^{15}$ Sus actas en Pérez Puente, L. 2010. El concierto imposible los concilios provinciales en la disputa por las parroquias indígenas (México, 1555-1647). México: Universidad Nacional Autónoma de México. (La Real Universidad de México, estudios y textos).

${ }^{16}$ Juarros, D. 1808. Compendio de la historia de la ciudad de Guatemala. I: 275-276. Guatemala: Ignacio Beteta. 
proveía de parroquias a clérigos desterrados de Portugal y Génova, así como a los miembros de su cabildo, quienes, por tanto, descuidaban sus prebendas y la misma catedral, que estaba toda cubierta de paja. De igual forma, en las relaciones enviadas a la Corte, se le acusó de tener en su casa a mujeres que no eran sus parientes y, en fin, las denuncias contra el obispo fueron tales que se ordenó a Moya de Contreras enviar un ministro a Guatemala por vía de visita, para informar de lo que sucedía allí. ${ }^{17}$

Con todo, la visita del metropolitano no se llevó a cabo, pues poco tiempo después de esos conflictos, Villalpando murió. Por eso anota Fuentes y Guzmán, que «hallando desfavorecidos y quejosos de su antecesor Villalpando a las religiones», el obispo Fernández de Córdoba quiso fomentarlas y consolarlas dándoles diversos curatos que quitaba a los clérigos.

Cuando Fernández de Córdoba tomo el gobierno episcopal de Guatemala la feligresía del obispado estaba distribuida con bastante equidad entre clérigos seculares y regulares. Los primeros administraban los sacramentos a 27.900 vecinos y los frailes a $28.150 .{ }^{18} \mathrm{~A}$ pesar de esa paridad, había 38 parroquias a cargo del clero secular, mientras los dominicos sólo poseían nueve, los franciscanos seis y los mercedarios cinco. Por ello el obispo restituyó a los frailes las doctrinas de que habían sido despojados por su antecesor y respaldó las peticiones de los franciscanos para que el Rey les concediera más, así como limosnas para mantenerse. ${ }^{19}$

Además, según Fuentes y Guzmán, el obispo tramitó en la Corte que se pagaran 50,000 maravedís a los religiosos por la administración y asistencia de cada doctrina y, ${ }^{20}$ tiempo después, intercedió por los frailes en sus disputas con el presidente Mallen de Rueda, poniendo en entredicho a la ciudad por tratar de impedir que un novicio franciscano fuera llevado a la cárcel de corte. ${ }^{21}$

Según se lee en la Recordación Florida, la preferencia mostrada por el prelado hacia las órdenes religiosas, llevó al cabildo de la ciudad a levantar diversas quejas contra él y a pedirle que cumpliera las cédulas reales donde se disponía que en la provisión de beneficios se debía preferir a hijos legítimos de conquistadores y vecinos de la ciudad de Guatemala. El obispo respondió que, si bien eso era cierto, no se mandaba que los curatos fueran dados a clérigos. ${ }^{22}$

\footnotetext{
${ }^{17}$ Fuentes y Guzmán, A. F. 1933: 255-256.

${ }^{18}$ Memoria del licenciado Mendiola de Arteaga sobre los beneficiados, noviembre 16 de 1570, AGI, Guatemala, 394, L. 5, f. 49v-51v.

${ }^{19}$ AGI, Guatemala, 394, L. 5, f. 233 e Informaciones de la orden de San Francisco en Guatemala de 1574, AGI, Guatemala, 113, N. 38.

${ }^{20}$ Fuentes y Guzmán, A. F. 1933: 279.

${ }^{21}$ Ibídem.: 291.

${ }^{22}$ Ibídem.: 321 . El término beneficio se refiere al fondo de donde se extrae la retribución de quien ejerce una función religiosa; al mismo tiempo se utiliza para hacer alusión a dicha función religiosa con 
De acuerdo con Fuentes y Guzmán, a esa actitud de Fernández de Córdoba se debió la expedición de la famosa cédula de 1583, donde se dispuso que habiendo clérigos idóneos y suficientes para ocupar las doctrinas indígenas, fueran éstos preferidos en lugar de los frailes. ${ }^{23}$ Sin embargo, esa orden real no tuvo aplicación en Guatemala pues, según el cronista, fue guardada por el prelado, y cuando el cabildo de la ciudad la conoció ya era demasiado tarde, pues un nuevo mandato la revocó en 1585. ${ }^{24}$

Tenga o no razón Fuentes y Guzmán en que el obispo de Guatemala estaba más inclinado a las órdenes religiosas que a la clerecía secular, la suya es una figura obscurecida en la historiografía por la fuerza del gobierno episcopal de su antecesor y, sobre todo, por la gran personalidad y la obra de Francisco Marroquín, primer obispo de Guatemala.

La poca atención a Fernández de Córdoba y al seminario conciliar cuya fundación ordenó, en parte se han debido a que buscando una identidad y un patrimonio original que diera consistencia y cohesión social a la iglesia guatemalteca, ésta se volcó con énfasis en el legado espiritual de su primer obispo, para así crear una mística fundacional. ${ }^{25}$ Con ese objetivo, la historiografía tradicional ha atendido a las gestiones hechas por Francisco Marroquín en pro de la educación de la juventud y, sobre todo, a la historia del colegio de Santo Tomás de Aquino, creado con los bienes testamentarios de este prelado. Ello, a pesar de que su colegio tuvo una vida breve y se fundó más tardíamente y de manera más conflictiva que el seminario conciliar.

Quizá esa falta de atención al colegio de Nuestra Señora de la Asunción también se deba a que éste no fue diseñado estrictamente como un seminario tridentino, pues, si bien estaba pensado para dar instrucción a quienes aspiraban al sacerdocio, sus primeros ingresos económicos no fueron rentas eclesiásticas y su gobierno tampoco estuvo íntimamente vinculado a la figura episcopal ni al cabildo eclesiástico, como dispusiera Trento. Características que favorecieron su fundación y primeros años de desarrollo, pues evitó muchos de los conflictos vividos por los seminarios conciliares de otras diócesis.

sus obligaciones y cargas, esto es, al oficio. Su finalidad es garantizar el mantenimiento económico de los clérigos.

${ }^{23}$ La cédula en Encinas, D. 1945-46. Cedulario indiano recopilado por Diego de Encinas, reproducción facsímil de la edición única de 1596. I: 99-100. Madrid: Cultura Hispánica. De esta se enviaron copias fechadas en diciembre 6 de 1583 a todos los prelados de Indias.

${ }^{24}$ La cédula de 1585 en AGI, Indiferente, 427, L. 30, fs. 364-366.

${ }^{25}$ Mística que incluso recogió en 1944 la Universidad Autónoma y Nacional de Guatemala, pues no sólo retomo el nombre de la antigua institución virreinal «San Carlos» fundada en 1676, sino que afirmó, como hasta hoy lo hace, que la fundación se había debió a las gestiones que iniciara Marroquí en 1548. En oposición a esa tradición escribió Mata Gavidia que «El legado del obispo Marroquín [...] no autoriza a ningún historiador a declararlo como fundador de la Universidad de san Carlos» Mata Gavidia, J. 1954: 13. 
De LOS SENCILLOS COMIENZOS DE UNA PARTICULAR INSTITUCIÓN

El seminario de Nuestra Señora de la Asunción fue una obra social, colectiva. Su fundación fue esfuerzo del cabildo de la ciudad de Santiago de los Caballeros, del Rey, de la Audiencia, así como del celo de un grupo de eclesiásticos y los pobladores de la ciudad. Además, y como toda obra educativa realizada en Guatemala, el seminario conciliar debió también algo al legado del obispo Marroquín, pues sus solicitudes para que el Rey dotara con estudios a la ciudad, así como las hechas por quienes le precedieron tratando de cumplir su última voluntad, allanaron el camino del seminario.

Conocidas son las cartas de ese prelado al Rey donde solicitó desde 1545, preceptores de gramática, ${ }^{26}$ así como sus peticiones para el establecimiento de universidad y su testamento dado en 1563, con las instrucciones para la fundación del colegio de Santo Tomás. ${ }^{27}$

Según dispuso el obispo Marroquín, aquél colegio tendría por patrones a quienes fueran prior del convento de Santo Domingo y deán de catedral, los cuales administrarían los bienes dejados para ese efecto en su testamento. El proyecto implicaba la construcción de un edificio para albergar cierto número de colegiales, donde se leerían lecciones de artes, teología y otras ciencias. Dos de estas cátedras serían pagadas con la renta de los bienes del obispo y, además, «...el padre prior, por sí y por el convento, ha de poner dos lectores de artes y teología por espacio de seis años, sin interés». ${ }^{28}$

Si bien fueron varias las peticiones para que se cumpliera el legado de Marroquín, la insuficiencia de la renta impidió la creación del colegio, y sólo en 1620 el presidente de la Audiencia autorizó el inicio de las lecturas, mientras se recibía la confirmación real. Sin embargo, para entonces, el colegio no contaba con casas para los colegiales, pues sólo tenía un aula en un solar perteneciente al convento dominico donde, en teoría, debían leerse las cátedras de artes, teología y cánones. ${ }^{29}$ Hacia 1639, cuando los patronos aun peleaban en la corte la confirmación real, negada en un principio, arguyeron que no era necesario edificar una casa para colegiales, pues en la ciudad había un seminario con renta conveniente. ${ }^{30}$

En efecto, mientras las disputas y trámites para la fundación del colegio de Santo Tomás se desarrollaban, se creó en 1598 el seminario de Nuestra Señora de la Asunción, gracias a que contó desde sus inicios con rentas suficientes. Sin

${ }^{26}$ 1877. Cartas de Indias. Públicalas por primera vez el Ministerio de Fomento: 444-450. Madrid: Manuel G. Hernández.

${ }^{27}$ Las cláusulas del testamento en Mata Gavidia, J. 1954: 14-15.

${ }^{28}$ Ídem.

${ }^{29}$ Ibídem.: 66.

${ }^{30}$ Solicitud para que se guarden y cumplan los autos del consejo acerca de la fundación del colegio de Francisco Marroquín, AGI, Guatemala, 396, L. 11, f. 194-199v. Al no recibir la confirmación real, el colegio de Santo Tomás debió cerrar sus cátedras en 1631.

Hispania Sacra, LXIV

129, enero-junio 2012, 187-210, ISSN: 0018-215-X, doi: 10.3989/hs.2012.006 
embargo, no se trataba de rentas eclesiásticas como había dispuesto Trento, sino de donaciones y limosnas hechas por los vecinos de la ciudad.

En 1598 se contaban entre los haberes del seminario 300 tostones del padre Lope Ortiz de Zárate, hijo de un encomendero; ${ }^{31}$ una renta de 650 tostones de dos capellanías fundadas por el clérigo Esteban López; 400 más, legados por Pedro de Arroyo para el sustento de dos colegiales; la renta de siete tiendas dadas por el clérigo Hernando de Escobar, que reportaban entre 65 y 70 tostones cada una; 214,50 tostones de un capital puesto a censo y, al parecer, había 100 pesos más pagados por la catedral para el salario del preceptor de gramática. ${ }^{32}$ Lo cual sumaba alrededor de $1.704,50$ tostones anuales $(852,25$ pesos de oro común), sin considerar el salario de la cátedra ni la renta de cuatro de las tiendas, pues no todas se beneficiaban.

A esos recursos se agregaron, en un principio, las limosnas recolectadas el año anterior por el obispo Fernández de Córdoba y dos oidores, tanto en la ciudad de Santiago de los Caballeros como en los pueblos vecinos. Entre ellas, una de 1.000 tostones de la audiencia, hecha en nombre del Rey. ${ }^{33}$ Desde su fundación el seminario contó, además, con una de las principales casas de la ciudad, situada junto a la iglesia mayor y la casa episcopal, donación de Hernando de Escobar. ${ }^{34}$

Con ese caudal el colegio abrió sus puertas en enero de 1598 a los primeros seminaristas, que eran seis colegiales mayores, seis menores, un familiar y su rector.

Aunque el obispo no firmó la fundación por hallarse enfermo, sí los estatutos que la acompañaron, pues fueron dispuestos en agosto del año anterior. ${ }^{35} \mathrm{Se}$ trató de 40 normas donde se regulaba quiénes integrarían el colegio, cómo se gobernarían y viviría en su interior, pero donde nada se decía sobre el sostenimiento económico de la institución. ${ }^{36}$

Debido a ello, quince días después de la apertura, el rector Esteban López, quien tuvo un papel destacado en el proceso de fundación, ${ }^{37}$ inició las negocia-

\footnotetext{
${ }^{31} \mathrm{El}$ tostón era la denominación dada a la pieza de 4 reales, equivalentes a medio peso de oro común o 136 maravedís. En 1587 un juez podía recibir 8 tostones diarios y 2 un escribano. Mientras que el catedrático de gramática de la ciudad recibía 400 tostones anuales. AGI, Guatemala 395, L. 6, f. 270v. Garza, M. 1992. Literatura Maya: 189. Caracas: Biblioteca Ayacucho.

${ }^{32}$ Informaciones del colegio de la Asunción de Guatemala, AGI, Guatemala, 115, N. 41. El capital que reportaba los 214,50 tostones procedía de las limosnas colectadas por el obispo.

${ }^{33}$ AGI, Guatemala, 395, L. 7, f. $19 \mathrm{v}$.

${ }^{34}$ Las casas habían sido de Diego Ramírez, «por cuyo fin y muerte, en la almoneda que se hizo de sus bienes, las sacó çlvaro de Aguilar, vecino de esta ciudad en nombre del padre Hernán Sánchez de Escobar». AHAG, Fondo diocesano, Seminario, C. 2. Constituciones.

${ }^{35}$ Ídem., e Informaciones del colegio de la Asunción de Guatemala, AGI, Guatemala 115, N. 41.

${ }^{36} \mathrm{AHAG}$, Fondo diocesano, Seminario, C. 2. Constituciones.

${ }^{37} \mathrm{Al}$ año siguiente de haberse creado el seminario, Esteban López ocupó una canonjía en la catedral de Guatemala para la que había sido nombrado en septiembre de 1597 y, luego, en 1602 se le nombró para el arcedianato, AGI, Patronato, 293, N. 19, R. 6 y N. 24, R. 88.
} 
ciones para asegurar las rentas e incrementarlas. Para ello, solicitó una información con testigos sobre la utilidad que reportaría el seminario, la hacienda con la que contaba, la renta anual necesaria para sustentar a los colegiales y pagar salarios a los catedráticos.

Todos los testigos aludieron a la gran conveniencia del colegio, señalaron que en él se leía gramática e hicieron referencia a la casa legada por Hernando de Escobar. Aunque no todos conocían los detalles de las rentas, la mayoría apoyó lasolicitud del rector, con la excepción del regidor Diego de Guzmán. Éste declaró que le parecían suficientes sólo 600 pesos anuales, pues a ello se debería sumar lo que aportaran los beneficios eclesiásticos, «pues es colegio seminario, fundado conforme al santo concilio», arguyó. ${ }^{38}$

Lo dicho por el regidor tenía sentido, pues de acuerdo con Trento, los seminarios debían sostenerse de rentas eclesiásticas. Forma de financiamiento que los distinguía de otros colegios, pues aseguraba que quedaran de manera exclusiva a cargo del obispo ósin importar quién fuera ésteó, y no de patronos particulares, o sujetos a la influencia de las autoridades locales. En ese sentido, por ejemplo, el colegio de Corpus Christi de Valencia no fue un seminario tridentino, pues al menos la mitad de él se había erigido con caudales propios del obispo Don Juan de Rivera. ${ }^{39}$

Algo similar sucedió en el colegio de la Asunción, donde a cambio de sus contribuciones los patronos adquirieron derechos sobre el nombramiento de colegiales. Hernando de Escobar se reservó la presentación de quienes ocuparían cinco de las colegiaturas y Pedro de Arrollo, dos más.

Así, en su fundación, el seminario de la Asunción distó del modelo tridentino, pareciéndose a muchos otros colegios de patronos particulares, incluso poco tiempo después, el más importante de sus patronos sería el Rey.

El objetivo de la información hecha por el rector en 1598 no era solicitar una limosna, sino que el Rey concediera al colegio un ingreso estable de 2.000 pesos de oro de minas anuales (3.308,8 pesos de oro común). Con ello se pretendía pagar cátedras de gramática, retórica, artes, teología, cánones y casos de conciencia, incrementar el número de colegiales y, finalmente, convertir el establecimiento en una universidad. ${ }^{40}$ «...pues para la población de gente que al presente hay en esta ciudad y su distrito, como para el aumento en que cada

\footnotetext{
${ }^{38}$ Informaciones del colegio de la Asunción, AGI, Guatemala, 115, N. 41.

${ }^{39}$ Barrachina Estevan, P. 1947. «Figura jurídica del Colegio de «Corpus Christi» de Valencia». Revista española de derecho canónico II, 5: 439-483.

${ }^{40}$ La renta solicitada era mínima pues en 1600-1601 la universidad de México teóricamente recibía de la real hacienda 7.941,125 pesos de oro común. Martínez López Cano, P. 2005. «Acercamiento a los ingresos de la universidad de México en la primera mitad del siglo XVII», en E. González González y L. Pérez Puente (ed.), Permanencia y Cambio. Universidades hispánicas, 1551-2001. I: 249-276. México: Centro de Estudios sobre la Universidad -UNAM.
}

Hispania Sacra, LXIV

129, enero-junio 2012, 187-210, ISSN: 0018-215-X, doi: 10.3989/hs.2012.006 
día va, ha de ser muy necesario y aun cosa forzosa». ${ }^{41}$ No era, pues, aquél un proyecto para fortalecer el seminario tridentino, sino para crear una universidad pública de patronato real.

La petición no era excepcional, pues otros seminarios también habían pretendido otorgar grados y así convertirse en universidades. En 1599, o antes, el obispo de Quito había hecho una solicitud en ese sentido, al igual que en 1600 el obispo de Charcas y el de Cuzco. ${ }^{42}$

Las universidades públicas, o estudios generales, eran instituciones reales, pues estaban financiadas por el Rey. En ellas estudiantes y doctores podían tener acceso a los principales cargos de gobierno, llegar a ser sus rectores y sus catedráticos. Además, a través de órganos colegiados, la comunidad velaba por sus intereses corporativos, dictaba estatutos para su marcha cotidiana, supervisaba el funcionamiento de las aulas, controlaba su administración, su hacienda y, sobre todo, el otorgamiento de los grados académicos, los cuales constituían requisitos indispensables para la promoción social.

En sustento de su solicitud, el rector Esteban López volvió a escribir al Consejo en noviembre de $1599,{ }^{43}$ señalando cómo siempre había sido deseo de Felipe II que no sólo se fundase y erigiese un colegio en Guatemala, sino que hubiese universidad y, para probarlo anexó a su nueva petición un capítulo de carta escrita por el Rey a Marroquín en $1549 .{ }^{44}$

Con todo, el colegio no recibió la merced pedida por su rector para transformarse en universidad pública. No obstante, poco a poco fue haciéndose de un mayor número de rentas no eclesiásticas, lo cual le permitió mantener abiertas sus puertas e incrementar el número de colegiales y cátedras. A mediados de 1601, cuando se volvió a despachar al Consejo de Indias la petición de 1599, temiendo que el correo se hubiese perdido, la Real Audiencia anexó su parecer señalando que para entonces había quince colegiales, tres más que en la fundación, «y aunque es seminario, y que los colegiales sirven en la iglesia catedral ordinariamente, no les da nada la iglesia para su sustento...». ${ }^{45}$ En ese sentido,

\footnotetext{
${ }^{41}$ Informaciones del Colegio de la Asunción de Guatemala. AGI, Guatemala 115, N. 41.

${ }^{42}$ Véase Guibovich Pérez, P. M. 2006. «Como GŸelfos y Guibelinos: Los colegios de San Bernardo y San Antonio abad en el Cuzco durante el siglo XVII». Revista de Indias 236: 107-132.

${ }^{43}$ Esta nueva misiva fue en respuesta a una cédula real donde se pedían informes a la Audiencia, catedral y cabildo de la ciudad sobre la situación del seminario y su renta, cómo se gastaban los dos novenos de los diezmos que pertenecían al Rey y en qué se le podría hacer merced al seminario, AGI, Guatemala, 395. L. 7, f. 29v-31v.

${ }^{44}$ En él se decía: «...lo que decís que convendría mandarse a la persona que hubiere de hacer la discreción y repartimiento de los indios de esa tierra, que señale un buen pueblo en esa provincia para un estudio que en ella se haga a manera de universidad, con esta os mando enviar cédula nuestra para que el licenciado Cerrato, nuestro presidente de la Audiencia real de los Confines, a quien está cometida la dicha discreción, tenga consideración a dejar en ella alguna cosa para el dicho estudio, como por ella veréis.» Cédula real dirigida a Francisco Marroquí en abril 29 de 1549 en AGI, Guatemala 115, N. 41.

${ }^{45}$ Parecer de la Audiencia de mayo 13 de 1601, AGI, Guatemala, 115, N. 41.
} 
el cabildo secular de la ciudad solicitó a su vez, se dieran al colegio los dos novenos de los diezmos pertenecientes al Rey, pues, habiéndose dado a la catedral para reparos, hacia ocho años que no se ocupaban y pasaban a los oficiales reales. ${ }^{46}$

La pérdida del correo se confirmó, pues, desde noviembre de 1600 el Rey había tomado cartas en el asunto, y había hecho merced al colegio de 800 ducados anuales (1.102,9 pesos de oro común) por cuatro años. Además, había consultado a la Audiencia sobre los rubros en que se podría hacer esa donación a perpetuidad, fuera de la caja real, y sobre qué otros medios había para conservar la institución. ${ }^{47}$ Luego, hacia 1618, concedió nuevamente la merced de 800 ducados y se le dieron 4,000 más, por una sola vez para ser utilizados en reparos. ${ }^{48}$

Esas sumas otorgadas por el Rey contribuyeron a alejar al seminario del modelo tridentino y lo acercaron al de una institución de patronato real. Fenómeno que se verifica también en las cátedras y en el gobierno interno del colegio dispuesto por las constituciones.

\section{EL GOBIERNO Y LAS CÁTEDRAS DEL SEMINARIO}

Las normas dadas por Fernández de Córdoba al colegio de la Asunción no pretendieron organizar hasta sus últimas consecuencias la vida del seminario, sino simplemente dar las bases legales para iniciar; es decir, estaban pensadas para dar vida a una institución que se esperaba se fuera definiendo al paso del tiempo. Así, en la constitución 39 se señaló que, puesto que algunas de las normas establecidas podrían con el tiempo llegar a causar inconvenientes «deseando y procurando desde ahora [...] el remedio de ello, ordenamos y establecemos que, en cualquiera tiempo que a nos y al prelado y prelados que no sucedieren pareciere alterar, innovar, mudar o revocar cualquier cosa de las por nos ordenadas, instituidas y establecidas, lo pueda hacer». ${ }^{49}$

Esa intención de su fundador explica la falta de disposiciones relativas a las fuentes económicas para el sustento del colegio, así como la distancia guardada por el obispo y el cabildo durante los primeros años de vida de la institución. $\mathrm{Y}$ es que, a diferencia de otros seminarios tridentinos, en las normas del guatemalteco se estableció que el gobierno y administración del seminario estarían a cargo de los mismos colegiales, y no del obispo ni de un miembro del cabildo de la catedral, como era usual.

\footnotetext{
${ }^{46}$ Carta del cabildo secular de Santiago de Guatemala, solicitando una renta para el Colegio de Nuestra Señora de la Asunción de abril 28 de 1601, AGI, Guatemala, 41, N. 98.

${ }^{47}$ Cédulas de noviembre 21 y 28 de 1600, AGI, Guatemala, 395, L. 7, f. 78v-79v.

${ }^{48}$ Cédula de octubre 10 de 1618, AGI, Indiferente, 450, L. A5, f. 167v.

${ }^{49}$ AHAG, Fondo diocesano, Seminario, C. 2. Constituciones. 
De acuerdo con las constituciones los colegiales debían ocupar los cargos de rector y consiliarios, y elegir al inicio de cada año a sus sucesores. Incluso, aún en caso de no poder llegar a un acuerdo sobre estas designaciones, la elección debía resolverse en el colegio, pues al tercer día pasaría al resto de los colegiales para que éstos designaran a los titulares (Const. 18). De igual manera, estaría a cargo de los estudiantes la administración de las rentas, el oficio de procurador de las causas legales y, como veremos, las lecturas de las cátedras y los oficios menores del colegio. Las visitas de las celdas, la disciplina interna, las reprimendas menores y castigos graves debían ser llevadas a cabo por el rector, quien, además, distribuiría las celdas, otorgaría los permisos, cuidaría que se llevaran a cabo las lecciones y actividades de recreación... en fin, los mismos colegiales dirigirían todo el seminario, incluyendo negocios legales y hacienda.

Con todo, el colegio no era totalmente autónomo, pues quedó reservado al obispo la reforma de las constituciones, el conocimiento de las «sentencias que causaren infamia o nota pública», la expulsión de los colegiales y algunas licencias. También a él correspondería nombrar a las dignidades catedralicias que visitarían al rector y colegiales ócuando el obispo lo señalaraó para hacer averiguación de su vida y costumbres, del cumplimiento de las constituciones y del ceremonial ordinario (Const. 38). Finalmente, tocaba al obispo, o su provisor, participar en la presentación de nuevos colegiales, aunque si la colegiatura vacante era de las pagadas por Hernando de Escobar, lo haría al lado de él o de quien tuviere su patronato (Const. 9). En las constituciones se establecía que la elección debía ser por medio de un concurso público de oposición, en el cual el obispo y los patronos sólo fungirían como examinadores.

Si bien los obispos tendrían facultad para modificar las constituciones, la amplia participación que en ellas se dio a los colegiales, muestra cómo en sus primeros años el seminario de la Asunción distó en mucho del modelo tridentino. En éste es el obispo el principal encargado del gobierno interno de los colegios, pues su objetivo no sólo era la instrucción de la clerecía, sino también fortalecer a la autoridad episcopal en el gobierno de las diócesis.

Ahora bien, por lo que hace a las lecturas, en las constituciones dictadas por el obispo Fernández de Córdoba se estableció que los colegiales se turnarían, por suertes, cada año o trienio para «comunicar su talento y trabajo a sus próximos», es decir, para impartir lecciones. Estas debían ser de gramática y retórica; cánones o casos de conciencia; escritura sagrada, homilía, computo eclesiástico y «lo que fuere necesario para oír confesiones y administrar los demás sacramentos» (Const. 14). Finalmente, debían hacerse ejercicios de canto llano, canto de órgano y de las ceremonias de la iglesia. No se había plateado la existencia de lecturas a cargo de catedráticos asalariados, sino de lecciones conducidas por los mismos colegiales. El seminario, pues, no había sido diseñado por Fernández de Córdoba para ser una universidad y, al parecer, tampoco un colegio 
con cátedras formales, sino sólo una residencia u hospedería de escolares que, dirigida por ellos, estaría dedicada al estudio y repaso de lecciones.

Con independencia de lo estipulado en las constituciones, en casi todas las cartas turnadas al Rey solicitando rentas se hacía mención de un número y tipo distinto de lecciones del seminario. En unas se dijo que se leía la gramática y se enseñaba canto; en otras, que además se impartían lecciones de sacramentos y, en las cédulas reales se mencionaban cátedras de artes, teología y casos de conciencia. Esa falta de precisión se debe a que, con la intención de obtener el favor real, se mezclaban proyectos de instituciones muy diferentes: un colegio residencia u hospedería, un colegio con cursos, una universidad. De igual forma, se combinaban las cátedras que se aspiraban a tener, con las lecturas cursadas por los colegiales en otras instituciones y con aquellas que, efectivamente, se impartían en el aula del seminario, construida desde 1599 en el espacio de dos de las siete tiendas del edificio. ${ }^{50}$

Según se desprende del conjunto de documentos, quizá desde la fundación, y acorde con lo dispuesto en las constituciones, los colegiales ejercitaron el canto en la catedral, sin que hubiese una cátedra pagada ex profeso para ello. Lo mismo sucedió con las lecciones de sacramentos y casos de conciencia, pues se sabe que en 1601 el tesorero de la catedral las impartía «después de acudir a sus obligaciones [...] y a los pobres se les enseña de gracia». ${ }^{51}$

No hay indicios de que en los primeros años se hubiese leído retórica, pero la gramática fue la primera de las cátedras asalariadas del seminario. En el primer año de creación del colegio la catedral contribuyó a la paga de un catedrático con 100 pesos de minas y, posteriormente, la financió el Rey por intervención del cabildo de la ciudad, el cual desde muy temprano y de forma constante hizo solicitudes para ello.

Desde 1576 el cabildo secular solicitó al Rey, como en su tiempo lo hiciera Marroquín, que autorizara la creación de una universidad, pues iría en gran provecho y aumento de los vecinos. Según señalaron, el lugar era apropiado, pues era tierra templada, «sana y abundante de mantenimientos, próspera de todos los metales ricos». ${ }^{52}$ En ella, además, se asentaba una Real Audiencia, era cabeza de obispado y había monasterios de la orden de Santo Domingo, San Francisco y la Merced «donde hay muy buenos letrados».

Para la fundación, que se esperaba fuera a semejanza de la universidad de México, se dijo al Rey que se podría disponer del colegio de Santo Tomás, pues este tenía un pequeño cuarto donde se leía gramática, y espacio para edificar

\footnotetext{
${ }^{50}$ Informaciones del Colegio de la Asunción de Guatemala, AGI, Guatemala, N. 41.

${ }^{51}$ Carta del cabildo secular de Santiago de Guatemala de abril 18 de 1601, AGI, Guatemala, 41, N. 98.

${ }^{52}$ AGI, Guatemala, 394, L. 5, f. 228-229v.
}

Hispania Sacra, LXIV

129, enero-junio 2012, 187-210, ISSN: 0018-215-X, doi: 10.3989/hs.2012.006 
todo lo necesario para el nuevo estudio. ${ }^{53}$ Sin embargo, la solicitud no prosperó y, debido a ello, el cabildo volvió a escribir a la corte en 1581 pidiendo 1,000 pesos de renta anual para la paga de catedráticos de la futura universidad. La petición se volvió a negar, pues no se había autorizado un estudio general, sin embargo el Rey convino en dar a la ciudad 200 pesos anuales para un preceptor de gramática y ${ }^{54}$ tiempo después, ratificó la merced por seis años ${ }^{55}$ Desde entonces, y por lo menos hasta 1630, la ciudad renovó la solicitud cada quinquenio antes del vencimiento del plazo, y recibió la merced. ${ }^{56}$

Esa cátedra, que no tenía un lugar fijo para su lectura, pasó al seminario en torno a 1600 , y ya en 1613 se aludía a ella como a «la cátedra de gramática del seminario de la ciudad». ${ }^{57}$ Así, esa lectura del seminario no fue dispuesta por el obispo ni tampoco pagada de rentas eclesiásticas, como se había dispuesto en Trento, sino que fue conseguida por la ciudad de Guatemala y financiada por el rey.

Finalmente, por lo que hace a los cursos de artes y teología, si bien desde 1599 se dijo eran impartidos en el seminario, no era así. En 1601 el rector Esteban López solicito al Rey renta para pagar a un catedrático que impartiera esas lecciones en el colegio, pues explicó que los estudiantes tenían que oír artes en «el convento de Santo Domingo con mucha descomodidad, por salir del recogimiento que tienen». ${ }^{58}$ En efecto, por lo menos desde 1578 los dominicos tenían cursos de artes, teología y gramática a los cuales solían asistir los seminaristas. ${ }^{59}$ En respuesta a aquella petición el rey pidió a la Audiencia que le indicara quién podría hacerse cargo de las nuevas lecturas, en caso de ser convenientes, qué salario podría dárseles y en dónde se impartirían.

Mientras los informes llegaban a la Península y aquella resolución se tomaba, el convento dominico continuó con sus lecturas, los jesuitas abrieron su colegio de San Lucas en 1606 con cátedras de gramática, retórica, artes y teología y, ${ }^{60}$ hacia 1620 el colegio de Santo Tomás se inició con las mismas cátedras. Aunque la ciudad se animaba con nuevos colegios y lecciones, eso no fue en detrimento de las solicitudes del seminario, pues el Rey autorizó que éste abriera cátedras

\footnotetext{
${ }^{53}$ Quizá se daba por sentado que al menos una de las cátedras leídas en el convento dominico era de las convenidas en el testamento de Marroquín, pues como sabemos, el colegio de de Santo Tomás no se fundó hasta 1620 .

${ }^{54}$ AGI, Guatemala, 395, L. 6, f. 93v.

${ }^{55}$ AGI, Guatemala, 395, L. 6, f. 182. Luego, en 1589, antes de que el plazo venciera, Francisco de Pedroza, quien se había hecho cargo de la lectura, pidió que se le aumentara el salario a 500 pesos anuales y éste fuera de por vida. AGI, Guatemala, 395, L. 6, f. 270v.

${ }^{56}$ De ello existe constancia por lo menos hasta 1630, AGI, Guatemala, 42, N. 28.

${ }^{57}$ Memorial del cabildo secular de Santiago de Guatemala, agosto 31 de 1616, AGI, Guatemala, 42, N. 13.

${ }^{58}$ AGI, Guatemala, 386, L. 2, f. 158-159.

${ }^{59}$ Sobre esa asistencia AGI, Guatemala, 118, N. 8 y sobre los estudios del convento en 1578, AGI, Guatemala, 394, L. 5, f. 305v-306v.

${ }^{60}$ Mata Gavidia, J. 1954: 42.
} 
propias de artes, teología moral y escolástica entre 1618 y $1620 .{ }^{61}$ De ello da constancia una información de oficio del seminarista Juan Luis de Escobar, de quien se dijo «comenzó a oír artes en el convento de Santo Domingo de esta ciudad y después las prosiguió en el dicho colegio [el seminario], donde acabó de oír otro curso de artes y asimismo a oído en él, teología moral y escolástica con mucha puntualidad». ${ }^{62}$

Así, desde principios del siglo XVII, al margen de los conflictos por la fundación del colegio de Santo Tomás y de los acalorados pleitos que a partir de 1624 se dieron entre éste, los dominicos y los jesuitas por gozar del privilegio de otorgar grados académicos ${ }^{63}$ el seminario de la Asunción fue creciendo de manera paulatina en número de cátedras, de colegiales y, finalmente, de rentas.

Ese desarrollo experimentado a principios del siglo se debió, en buena medida, a la cercanía del colegio con los poderes reales, pues, por entonces, el seminario pasó a ser considerado de patronato real. «Como patrón que soy del dicho colegio» ${ }^{64}$ escribió el Rey a la Audiencia en una de sus cédulas de 1618, solicitando información sobre la fundación, rentas y mercedes del seminario. Como vicerrector del «Colegio Real de Nuestra Señora de la Asunción», ${ }^{65}$ se presentó a sí mismo el presbítero Juan Luis de Escobar en 1620 y, finalmente, en 1644 un escribano de la ciudad le llamó «Colegio Real y Seminario de NuestraSeñora de la Asunción», ${ }^{66}$ al dar constancia de un acto literario de conclusiones teológicas celebrado en él.

Ese carácter real atribuido al seminario se debía, en parte, al reconocimiento del patronazgo del Rey en Indias, que debía hacer la institución. De hecho, la cédula real turnada de manera general para la fundación de los seminarios conciliares en América, señalaba que los prelados podrían poner sus armas en las casas de los colegios, siempre y cuando se pusieran también las reales en más preeminente lugar. ${ }^{67}$ Sin embargo, ninguno de los seminarios conciliares hasta entonces creados en Indias había llevado el apelativo de real, pues ello hubiera

\footnotetext{
${ }^{61}$ Datos al respecto en AGI, Indiferente, 450, L. A5, f. 167v, 227v-228.

${ }^{62}$ Informaciones de Juan Luis de Escobar de 1620, AGI, Guatemala, 122, N. 1.

${ }^{63}$ En 1624 el estudio dominico pasó a ser universidad conventual al conseguir del Rey licencia para otorgar grados académicos por diez años; por su parte, y siempre en competencia con los anteriores, los jesuitas consiguieron análogo privilegio de graduar en 1626 para su prestigiado Colegio de San Lucas y luego en 1640 lo adquirieron a perpetuidad. La concesión a los dominicos en AGI, Guatemala, 395, L. 9, f. 67-67v. Sobre las competencias por el otorgamiento de grados: Peset, M. 2000. «Espacio y localización de las universidades hispánicas». Cuadernos del Instituto Antonio de Nebrija 3: 189-232; Guibovich Pérez, P. M. 2006. 107-132; Pérez Puente, L. 2010. «San Carlos de Guatemala. Universidad pública o universidad conventual». Revista Iberoamericana de Educación Superior 1, 2: 25-46.

${ }^{64} \mathrm{AGI}$, Indiferente, 450, L. A 5, f. $167 \mathrm{v}$.

${ }^{65}$ AGI, Guatemala, 122, N. 1.

${ }^{66}$ AGI, Indiferente, 112, N. 108.

${ }^{67}$ Cédula general para la fundación de seminarios, junio 22 de 1592, AGI, Indiferente, 427, L. 30, f. $435 \mathrm{v}-436 \mathrm{v}$.
} 
resultado contraproducente a los obispos fundadores, quienes habían peleado incesantemente para que se reconociera que el gobierno, administración, nominación de los colegiales, catedráticos y ministros de los seminarios correspondía de forma exclusiva al prelado, para evitar la intromisión de virreyes y Audiencias.

En Lima el virrey marqués de Cañete había mandado tomar posesión del colegio de Mogrovejo, defendiendo precisamente la tesis de que, puesto que el Rey era patrono universal de las Indias, lo era también de cualquier seminario fundado en ellas. ${ }^{68}$ Con ese mismo argumento pretendió disponer sobre la elección de colegiales, ordenó picar el escudo arzobispal labrado en la fachada de establecimiento, hizo nombramiento de mayordomo y exigió tomar cuentas a la administración. ${ }^{69}$

En Quito, las mismas ideas fueron esgrimidas por la Real Audiencia con la intención de obligar al obispo fray Pedro de la Peña a dotar las cátedras del seminario por concurso de oposición, conforme al patronato. ${ }^{70}$ Más aún, el presidente de aquella Audiencia señaló que la mayor parte del seminario la pagaba el rey, pues lo aportado por los frailes y clérigos seculares al seminario provenía de los tributos. Por tanto, bien se podría considerar al seminario como un establecimiento de carácter real, donde el Rey tenía la facultad de poner sus armas de forma exclusiva y de mandar a las Audiencias elegir a los colegiales. Aun más, sugirió el presidente de la audiencia, que para que el obispo no descuidara la institución, se le podría dar por merced el nombramiento de cierto número de colegiales. ${ }^{71}$

Así, a más del reconocimiento al patronato indiano, el carácter real adoptado por el seminario de Guatemala se debió a las mercedes reales con las cuales se había fundado, pues, como se ha señalado, no recibió en un principio rentas eclesiásticas; a lo cual se sumó la escasa presencia del obispo durante sus primeros años de vida. Y es que, por una parte, en las primitivas constituciones del seminario el obispo estaba poco involucrado en su conducción y, por otra parte, Fernández de Córdoba murió en 1598, el mismo año de la fundación, quedando la catedral en sede vacante hasta 1601, cuando tomó la mitra guatemalteca fray Juan Ramírez de Arellano, (1601-1609).

De esta forma, y a pesar de haberse subrayado en Trento el fuerte vínculo que debía existir entre los seminarios y el prelado, así como la intervención que en su marcha debía tener el cabildo catedralicio, ello no se verificó en los años

${ }^{68}$ La cédula en Salazar, J. A. 1946. Los estudios eclesiásticos superiores en el Nuevo Reino de Granada (1563-1810): 308. Madrid: Consejo Superior de Investigaciones Científicas / Instituto Santo Toribio de Mogrovejo.

${ }^{69}$ Cartas del arzobispo de Lima de marzo 23, 24, 27 y 31 de 1591, AGI, Patronato 248 R. 21.

${ }^{70}$ AGI, Quito, 82, N. 37.

${ }^{71}$ Carta del presidente de la Audiencia de Quito, abril 15 de 1595, AGI, Quito 8, R. 29, N. 125. 
de fundación del colegio guatemalteco, cuyo mayor apoyo recayó en el Rey, la Real Audiencia, la ciudad, un grupo de eclesiásticos y sus mismos colegiales.

\section{LA TRANSFORMACIÓN DEL COLEGIO}

En junio de 1603, cuando además de los colegiales el seminario tenía 10 pupilos óocho de los cuales pagaban su manutenciónó, el Rey solicitó a la Audiencia y al obispo fray Juan Ramírez, le informaran sobre la administración y rentas del colegio. ${ }^{72}$ La preocupación del monarca respondía a una solicitud del antiguo rector, Esteban López, ya arcediano de la catedral, el cual pidió al Rey que incrementara las mercedes hechas al seminario, pues, según explicó, el cabildo eclesiástico se había negado a contribuir para su sustento, alegando que hasta entonces el colegio sólo se mantenía de meras limosnas. Es decir que no era un seminario conciliar. ${ }^{73}$

Para regularizar la situación, al empezar el año siguiente, el obispo nombró a una comisión, prevista por Trento, para determinar el monto con que deberían contribuir anualmente las mesas episcopal y capitular, los novenos del diezmo, los curatos y los demás beneficios del obispado para el sostenimiento del colegio. En aquellas cuentas, donde no se contemplaba a ninguna de las doctrinas a cargo del clero regular, se estableció que el obispo pagaría 200 tostones, igual cantidad la mesa capitular y el conjunto de los novenos, con excepción de los dos correspondientes al Rey, debido a las grandes mercedes concedidas ya. Cada uno de los 46 beneficiados con cura de almas en el obispado debía pagar 30 tostones, con excepción de tres de ellos, que pagarían 50. ${ }^{74}$ Anualmente debían así reunirse 2.040 tostones (1.020 pesos de oro común). Para asegurar esa recaudación los curas fueron obligados a firmar una notificación y compromiso de pago, sin embargo los únicos que se negaron a firmar y pagar su parte fueron los miembros del cabildo eclesiástico.

En una reunión del cabildo de enero de 1605 el deán y uno de los canónigos señalaron que el concilio de Trento no daba facultad para hacer «pinción sobre los beneficios del patronato real», ${ }^{75}$ por lo cual no se avendrían a la paga del seminario, e incluso apelarían a Su Santidad y al metropolitano. El arcediano accedió a la solicitud siempre y cuando los colegiales «anduvieren derechamente en el servicio de esta santa iglesia» y otro canónigo señaló que daría lo que pudiera cuando Dios fuera servido de aumentar las prebendas y las capellanías.

\footnotetext{
${ }^{72}$ Cédula al obispo de Guatemala de junio 16 de 1603, AGI, Guatemala, 386, L. 2. F. 172v-173.

${ }^{73}$ Ídem.

${ }^{74} \mathrm{La}$ cuenta no contemplaba a los beneficiados de Xalapa y Suchitolo por ser muy pobres. Información sobre lo que se ha de contribuir anualmente al colegio seminario de la Asunción, AGI, Guatemala, 117, N. 6.

${ }^{75}$ Ídem. 
Más allá de los argumentos, la negativa se debía al hecho de que toda asignación para el seminario implicaba una merma de sus rentas. ${ }^{76}$

Ante ello, y usando de la facultad que le otorgaba el concilio de Trento, fray Juan Ramírez impuso una pena de 100 pesos de minas a quien estorbara o impidiera la cobranza, fuera clérigo o prebendado de la catedral. No obstante, los capitulares continuaron con su protesta y recurrieron a la Audiencia por vía de fuerza, quien falló en favor del prelado, señalando que debía procederse al cobro una vez que el Rey aprobara la distribución. ${ }^{77}$ Condición que hizo que nada se cobrara al cabildo en, por lo menos, los siguientes cinco años. ${ }^{78}$

Carezco de información sobre cómo o cuándo por fin se hizo efectivo el pago, no obstante es probable que los capitulares fueran obligados a contribuir entre 1610 y 1620, sobre todo porque el Rey no incrementó la merced de 800 ducados y, como vimos, en aquellos años el seminario contó con nuevas cátedras. Además, para entonces, el colegio empezó a sufrir cambios importantes.

En el manuscrito de las constituciones firmadas por Fernández de Córdoba están tachadas palabras, partes de algunos de sus decretos e incluso títulos completos. Posiblemente ello se deba a la revisión de las constituciones realizada por el obispo fray Juan Ramírez, quien no sólo pugnó porque se financiara de rentas eclesiásticas, sino que también trató de dotar al seminario de nuevas normas, para así sujetarlo a su jurisdicción y hacer de él un seminario más acorde con las disposiciones canónicas.

Entre los decretos suprimidos por el obispo se encuentra la constitución 18 referente a la elección de rector y consiliarios y, entre otras, las relativas a las facultades del rector para imponer disciplina, así como algunas de las menciones referentes a los patronos e incluso al provisor.

De esa reforma legislativa, que acusan los borrones del documento, se quejaron los colegiales ante el Rey en 1607, señalando cómo, el seminario se había gobernado desde su fundación por diversas constituciones, ${ }^{79}$ y queriendo el

\footnotetext{
${ }^{76}$ Por esos mismos años Juan de Castilla, procurador en la corte por la universidad de México estaba negociando la fundación de seminarios conciliares y se quejaba de que los prelados se negaban a renunciar a sus rentas. «porque los obispos no los harán jamás, porque algunos de ellos pasan acá a España sus rentas, y parece más llegado a piedad cristiana las gasten donde se las dan, en obras pías». AGI, Patronato 183, N. 1, R. 19.

${ }^{77}$ Ello a pesar de los múltiples conflictos de jurisdicción sostenidos entre los oidores y el obispo durante todo el gobierno episcopal de éste. AGI, Guatemala, 41, N. 102, así como Guatemala, 11, R. 5, N. 33; R. 6, N. 34 y R. 6, N. 36.

${ }^{78}$ Cédula real al cabildo y obispo de Guatemala, diciembre 20 de 1610, AGI, Guatemala, 395, L. 8, f. $67-67 \mathrm{v}$.

${ }^{79}$ Ignoro la fecha de la reforma del obispo Ramírez y cuáles pudieron haber sido esas diversas constituciones, lo más probable es que sólo se estuvieran refiriendo al conjunto de 40 normas dictadas por Fernández de Córdoba, pues éste murió poco tiempo después haberlas compuesto y el cabildo en sede vacante no tenía facultad para imponer nuevas.
} 
obispo fray Juan Ramírez poner solución a ello, les dictó otras que, sin embargo, resultaban peores que las primeras ${ }^{80}$ En particular, citaron un decreto que les obligaba a renunciar a su derecho de apelación ante cualquier autoridad fuera de la diocesana. Por eso solicitaron que se les concediera regirse por las constituciones del colegio mayor de la ciudad de México, esto es, el de Santa María de Todos los Santos.

Ese colegio, conocido como mayor, sólo alcanzó este título y los privilegios anejos a él en $1700 .{ }^{81}$ Víctor Gutiérrez señala que, en vista del poder y el prestigio de los colegios mayores, muchos se adjudicaron o pretendieron el título de mayor. Este fue el caso del de Santa María de Todo los Santos, que, como los mayores de España ${ }^{82}$ no ejercía docencia, era una congregación secular de estudiantes, clérigos o no, con vida en común y un gobierno autónomo. Entre las constituciones originales, redactadas por su fundador en 1573, se estableció que el gobierno y administración de las rentas del colegio estaría a cargo de su rector, elegido anualmente y por el colegio en pleno, entre los colegiales, al igual que los dos consiliarios y el secretario de capilla. La provisión de becas, destinadas a bachilleres graduados, tres legistas, tres canonistas y cuatro teólogos, era privativa de los mismos colegiales, y debían darse por concurso de oposición, previa entrega de probanzas de vida y costumbres, de limpieza y nobleza de sangre. ${ }^{83}$

Así, la solicitud de los seminaristas de la Asunción para adoptar las constituciones del colegio de Santos, tenía por objetivo romper el vínculo con el gobierno diocesano. Sin embargo, y conscientes de la dificultad para alcanzar la concesión, aspiraron al menos a que volvieran a estar vigentes sus primitivas constituciones. Por ello, pidieron que se ordenara que el rector fuera siempre un colegial, electo por votación de los mismos colegiales, el cual sólo podría ser removido por los consiliarios, «tal como se usaba en los demás beneficios del patronato real», esto es, con la intervención de la Audiencia ${ }^{84}$ Además, solicitaron que no se permitiera que el colegio quedara sujeto al cabildo de la catedral

${ }^{80}$ Cédula a la Audiencia de Guatemala, AHAG, Fondo diocesano, Seminario, C. 2. Constituciones, fs. $27-27 \mathrm{v}$.

${ }^{81}$ Gutiérrez Rodríguez, V. 1992. «El colegio novohispano de Santa María de Todos los Santos. Alcances y Límites de una institución colonial». Estudios de historia social y económica de América 9: 23-35.

${ }^{82}$ En sentido estricto sólo seis colegios ostentaron el título de mayores, cuatro en Salamanca: San Bartolomé, de Cuenca, de Oviedo y del Arzobispo; el vallisoletano de Santa Cruz y el de San Ildefonso, en Alcalá de Henares. Ídem.

${ }^{83}$ Arechederreta y Escalada, J. B. 1796. Catálogo de los Colegiales del insigne viejo y mayor de Santa María de Todos los Santos: 8-9. México: Mariano Joseph de Zúñiga y Ontiveros.

${ }^{84}$ Esa forma de nombramiento se respetó luego de que Esteban López renunciara a la rectoría del colegio en 1602, pues entonces «los colegiales eligieron rector, vicerrector y consiliarios entre ellos», y se siguió observando por lo menos hasta 1605, cuando fue electo Diego de Vargas. Véase AGI, Guatemala, 386, L. 2. f. 172v-173 e Informaciones de Diego de Vargas, AGI, México, 236, N. 6. 
durante las sedes vacantes, por ninguna vía ni manera, «así porque con estarlo se desautoriza mucho, por el inconveniente de la enemistad y odio grande que siempre tiene [el cabildo] a los colegiales, por cuya causa desean y pretenden estar sujetos a su rector». ${ }^{85}$

La rectoría no era un beneficio eclesiástico, como arg Ÿían los colegiales, ni los seminarios contemporáneos a él se gobernaban con la autonomía que deseaban para sí los estudiantes de Guatemala. En Lima, el colegio de Santo Toribio de Astorga tenía por rector a un sacerdote electo por el arzobispo; en el de San Bartolomé, de Santa Fe de Bogotá, creado en enero de 1605, era también un sacerdote electo por los superiores de la Compañía de Jesús, ${ }^{86}$ mientras en las constituciones del de Cuzco, dictadas aquél mismo año, se decía que sólo el prelado podría elegir rector y, en la sede vacante lo haría el provisor. ${ }^{87}$ En todos los casos debía tratarse de «un sacerdote de buena vida y ejemplo, de edad y prudencia para gobernar».

Si bien Trento no especificó nada al respecto de la designación de rector, era claro que no se trataba de un cargo de elección colegial, como tampoco lo era ninguno de los oficios de los seminarios. Al obispo correspondía la educación de los clérigos, era natural, por tanto, que, reservándose la autoridad del colegio, en él recayera de manera privativa el derecho de encomendar o no las tareas de su gobierno.

En apoyo de esa idea, todos los prelados americanos que hasta entonces se habían aventurado a fundar un seminario, habían peleado denodadamente contra virreyes y Audiencias, para hacer valer su jurisdicción. Como resultado de esas batallas, habían conseguido una serie de cédulas reales donde se reconocía su derecho exclusivo al gobierno, la administración y la nominación de los colegiales, la elección de catedráticos y encargados de su hacienda, la facultad para poner sus armas en las casas de los colegios, siempre y cuando se pusieran también las reales en más preeminente lugar; también habían logrado se ordenara contribuir a los frailes, hospitales y cofradías para el sostenimiento de los colegios, además de otras disposiciones referentes a los problemas particulares de cada unas de las diócesis. ${ }^{88}$

Así, y como era de esperarse, la petición de los seminaristas no prosperó, por lo que se impuso la reforma de las constituciones. De esta manera, hacia los años 20 del siglo XVII el seminario de la Asunción pasó a ser una institución distinta de la que había surgido en 1598.

${ }^{85}$ Cédula a la Audiencia de Guatemala AHAG, Fondo diocesano, Seminario, C. 2. Constituciones, fs. 27-27v.

${ }^{86}$ Salazar, J. A. 1946: 337.

${ }^{87}$ Las constituciones fueron editadas por Vargas Ugarte, R. 1940. Manuscritos peruanos de la Biblioteca Nacional de Lima: 44-57. Lima: Biblioteca Nacional de Lima.

${ }^{88}$ Pérez Puente, L. 2010. «Un seminario conciliar...»: 219-242. 
Desde su fundación había sido un colegio hospedería, de patronato real y particular que, alejado del prelado y del cabildo catedralicio, era dirigido por los mismos colegiales. Luego, hacia los años 20, ya dotado de cátedras propias, se pagaba en su mayor parte de rentas eclesiásticas y, debido a ello, así como a la reforma de sus constituciones, su gobierno quedó controlado por el obispo. A partir de entonces bien puede considerársele un seminario tridentino, aunque no cabalmente, pues el Rey no permitiría a los prelados gobernar de forma exclusiva esos colegios donde se formaba el clero de élite de la iglesia de sus territorios. ${ }^{89}$

La fundación del colegio de la Asunción es, pues, ejemplo de cómo, lejos de seguirse el modelo ideal plasmado en el concilio de Trento, los seminarios nacieron como proyectos particulares, muy distintos unos de otros. No sólo porque se asentaron en regiones diversas, sino también porque, en cada una, los poderes se articulaban de forma distinta, porque los obispos que les dieron forma respondían a unas determinadas circunstancias y, finalmente, porque cada prelado concibió a su manera la reforma de la iglesia, más allá de los dictados tridentinos y, en ocasiones, aún de las órdenes reales. «El tiempo -escribió Fernández de Córdoba, hacia el final de sus constituciones-, muda de manera el estado de todas las cosas, que es ordinario mudarse conforme a él la conveniencia y comodidad de ellas». ${ }^{90}$

\section{SigLAS Y BIBLIOGRAFÍA}

AGI Archivo General de Indias, España

AHN Archivo Histórico Nacional, España

AHAG Archivo Histórico de la Arquidiócesis de Guatemala, Guatemala

Arechederreta y Escalada, Juan Bautista. 1796. Catálogo de los Colegiales del insigne viejo y mayor de Santa María de Todos los Santos. México: Mariano Joseph de Zúñiga y Ontiveros.

Barrachina Estevan, Pablo. 1947. «Figura jurídica del Colegio de «Corpus Christi» de Valencia». Revista española de derecho canónico II, 5: 439-483.

Cartas de Indias. Públicalas por primera vez el Ministerio de Fomento. 1877. Madrid: Manuel G. Hernández.

«Constituciones que han de guardar los colegiales del Colegio Seminario de San Antonio Abad de la ciudad de Cuzco». 1940. En Rubén Vargas Ugarte (ed.), Manuscritos peruanos de la Biblioteca Nacional de Lima: 44-57. Lima: Biblioteca Nacional de Lima.

\footnotetext{
${ }^{89}$ Ejemplo claro es cómo en 1642 antes de aprobar las constituciones del seminario de San Francisco de Asís, de Popayán, se ordenó que debía quitarse el título de patrón que se atribuía al obispo dejándole sólo el de fundador. AGI, Quito, 215, L. 2, f. 136-137.

${ }^{90}$ AHAG, Fondo diocesano, Seminario, C. 2. Constituciones. Const. 39.

Hispania Sacra, LXIV

129, enero-junio 2012, 187-210, ISSN: 0018-215-X, doi: 10.3989/hs.2012.006
} 
El Sacrosanto y Ecumenico Concilio de Trento, traducido al idioma castellano por Don Ignacio López de Ayala, agrégase el texto latino corregido según la edición auténtica de Roma, publicada en 1564. 1785. Madrid: Imprenta Real.

Encinas, Diego de. 1945-46. Cedulario indiano recopilado por Diego de Encinas, reproducción facsímil de la edición única de 1596. vol. I. Madrid: Cultura Hispánica.

Fuentes y Guzmán, Antonio Francisco. 1933. Recordacion florida discurso historial y demostración natural, material, militar y política del Reyno de Guatemala. vol. III. Guatemala: Tipografía nacional.

Garza, Mercedes. 1992. Literatura Maya. Caracas: Biblioteca Ayacucho.

González Orellana, Carlos. 1960. Historia de la Educación en Guatemala. México: Costa Amic.

Guibovich Pérez, Pedro M. 2006. «Como Güelfos y Guibelinos: Los colegios de San Bernardo y San Antonio abad en el Cuzco durante el siglo XVII». Revista de Indias LXVI, 236: 107-132.

Gutiérrez Rodríguez, Víctor. 1992. «El colegio novohispano de Santa María de Todos los Santos. Alcances y Límites de una institución colonial». Estudios de historia social y económica de América 9: 23-35.

Hernández de Alba, Guillermo. 1969. Documentos para la historia de la educación en Colombia, 1540-1653. vol. I. Bogotá: Patronato colombiano de Ciencias y Artes.

Juarros, Domingo. 1808. Compendio de la historia de la ciudad de Guatemala. vol. I. Guatemala: Ignacio Beteta.

Martínez López Cano, Pilar. 2005. «Acercamiento a los ingresos de la universidad de México en la primera mitad del siglo XVII», en Enrique González González y Leticia Pérez Puente (eds.), Permanencia y Cambio. Universidades hispánicas, 1551 2001. I: 249-276. México: Centro de Estudios sobre la Universidad - UNAM.

Mata Gavidia, Jose. 1954. Fundacion de la universidad en guatemala, 1548-1688. Guatemala: Editorial universitaria.

Pérez Puente, Leticia. 2010. «Un seminario conciliar entre dos iglesias. Quito 15651583», en Jorge Correa (ed.), Facultades y Grados. X Congreso internacional de Historia de las universidades hispánicas. II: 219-242. Valencia: Universidad de Valencia.

Pérez Puente, Leticia. 2010. El concierto imposible los concilios provinciales en la disputa por las parroquias indígenas (México, 1555-1647). México: Universidad Nacional Autónoma de México. (La Real Universidad de México, estudios y textos 26).

Pérez Puente, Leticia. 2010. «San Carlos de Guatemala. Universidad pública o universidad conventual». Revista Iberoamericana de Educación Superior 1, núm. 2.

Pérez Puente, Leticia. 2012. «La fundación del seminario conciliar y el fortalecimiento de al jurisdicción episcopal, Lima 1564-1603», en Rodolfo Aguirre Salvador (ed.), Espacios de saber, espacios de poder. Iglesia, universidades y colegios en Hispanoamérica, siglos XVI-XIX: 74-97. México: Instituto de Investigaciones sobre la Universidad y la educación, UNAM.

Peset, Mariano. 2000. «Espacio y localización de las universidades hispánicas». Cuadernos del Instituto Antonio de Nebrija 3: 189-232.

Recopilación de leyes de los reinos de las Indias mandadas imprimir y publicar por la Magestad Católica del rey Don Carlos II. 1841. Madrid: Boix. 
Salazar, José Abel. 1946. Los estudios eclesiásticos superiores en el Nuevo Reino de Granada (1563-1810). Madrid: Consejo Superior de Investigaciones Científicas / Instituto Santo Toribio de Mogrovejo.

Salazar, Ramón A. 1897. Historia del desenvolvimiento intelectual de Guatemala. La colonia. vol. I. Guatemala: Tipografía nacional.

Suñe Blanco, Beatríz. 1997. «La educación en Guatemala (s. XVI) como un proceso de enculturación-aculturación», en Alfredo Jiménez (ed.), Antropología histórica: la Audiencia de Guatemala en el siglo XVI: 369-394. Sevilla: Universidad de Sevilla.

Vargas Ugarte, Rubén. 1969. Historia del seminario de Santo Toribio de Lima, (15911900). Lima: Empresa gráfica San Martí.

Vergara Ciordia, Javier. 2004. Historia y pedagogía del seminario conciliar en Hispanoamérica, 1563-1800. Madrid: Dykinson.

Vergara Ciordia, Javier. 2005. «Datos y fuentes para el estudio de los seminarios conciliares en Hispanoamérica: 1563-1800». Anuario de Historia de la Iglesia 14: 239300. 